Research Square
Preprints are preliminary reports that have not undergone peer review.

They should not be considered conclusive, used to inform clinical practice, or referenced by the media as validated information.

\title{
Efficacy and safety of convalescent plasma therapy for severe COVID-19 patients $\llbracket$ case series study and literature review
}

Jinbao Huang ( $\sim$ huangnbao0@126.com )

The People's Hospital Affiliated to Fujian University of Traditional Chinese Medicine;

Changqing Lan

Fuzhou Pulmonary Hospital of Fujian, Educational Hospital of Fujian Medical University;

\section{Research Article}

Keywords: COVID-19, SARS-CoV-2, convalescent plasma, tomography, X-ray computed

Posted Date: February 2nd, 2022

DOl: https://doi.org/10.21203/rs.3.rs-1223109/v2

License: @) (1) This work is licensed under a Creative Commons Attribution 4.0 International License. Read Full License 


\section{Abstract}

Background: Coronavirus disease 2019 (COVID-19) is a new acute respiratory infectious disease that can lead to multiple organ dysfunction in severe patients. However, there is still a lack of effective antiviral drugs for COVID-19. Herein, we investigated the efficacy and safety of convalescent plasma (CP) in the treatment of severe COVID-19 in an attempt to explore new therapeutic methods.

Methods: Clinical data of three imported severe COVID-19 patients with CP treatment who were under quarantine and treated in a designated COVID-19 hospital from March 2020 to April 2020 were collected and analyzed.

Results: The three patients were clinically classified as severe type, including one male and two females, aged 57, 59 and 65 years old, respectively. The main underlying diseases included hypertension, diabetes, sequelae of cerebral infarction and postoperative thyroid adenoma. The common symptoms included cough, fever and shortness of breath. All patients received antiviral drugs and other supportive treatments. Additionally, CP treatment was also administered. Forty-eight to seventy-two hours after CP transfusion, all the patients improved with alleviated symptoms, elevated arterial oxygen saturation, and decreased C-reactive protein and interleukin-6 markers. Total lymphocytes, T lymphocytes (CD3+) and their subsets (CD4+, CD8+) were also obviously increased. Repeated chest CT also showed obvious absorption of lesions in the bilateral lungs. Only one patient had a mild allergic reaction during CP infusion, but no severe adverse reactions were found.

Conclusions: The early application of CP for severe COVID-19 patients can improve the condition rapidly, and the therapy is generally effective and safe.

\section{Introduction}

Coronavirus disease 2019 (COVID-19) induced by severe acute respiratory syndrome-associated coronavirus-2 (SARS-CoV-2) is a new acute respiratory infectious disease that can lead to multiple organ dysfunction in severe patients [1]. Worryingly, the infection remains worse in most countries and areas. As of January 2, 2022, the COVID-19 epidemic has caused more than 289 million cases and over 5.44 million deaths worldwide

(https://coronavirus.jhu.edu/map.html). However, there is still a lack of effective antiviral drugs for COVID-19 [1, 2]. Convalescent plasma (CP) therapy has been used for treating influenza for more than a century. A meta-analysis of 32 studies showed that CP therapy could reduce mortality in influenza virus patients [3]. Currently, several clinical studies have shown that CP therapy can significantly improve the clinical symptoms and prognosis of severe and critically ill COVID-19 patients [4-6]. A randomized controlled trial in China further revealed that early infusion of CP had a better therapeutic effect in COVID-19 patients, and more benefits could be obtained in severe patients than in life-threatening patients [7-8]. This study retrospectively analyzed the clinical data of three severe COVID-19 patients who received CP therapy and obtained good curative effects to further improve the understanding of the application value of this therapy in severe COVID-19 patients.

\section{Materials And Methods}

\section{Patients}

Clinical data, including epidemiology, clinical manifestations, laboratory examinations, imaging results and treatment outcomes, were collected from three imported severe COVID-19 patients who were under quarantine and treated in a designated hospital in Fuzhou from March 2020 to April 2020 . The last follow-up was completed on May 7, 2020. Respiratory tract specimens (throat swabs) of all enrolled cases were positive for SARS-CoV-2 RNA by reverse transcription-polymerase chain reaction (RT-PCR) qualitative detection. All patients met the diagnostic criteria according to the Diagnosis and Treatment Program for COVID-19 issued by the National Health and Family Planning Commission [9].

The disease severity in COVID-19 patients was classified as follows : Mild COVID-19 was defined as mild clinical symptoms without pneumonia on chest imaging; Moderate COVID-19 was defined as clinical symptoms (e.g., fever and respiratory symptoms) with limited pneumonia on chest imaging; Severe COVID-19 was defined as any of the following: respiratory distress and respiratory rate $\geq 30$ breaths per minute, or in resting state, oxygen saturation $\leq 93 \%$ on room air, or arterial partial pressure of oxygen $\left(\mathrm{PaO}_{2}\right) /$ fraction of inspired oxygen $\left(\mathrm{FiO}_{2}\right) \leq 300$, or significant lung lesion progression $\otimes 50 \%$ within 24 to 48 hours on chest imaging; Critically ill (Life-threatening) COVID-19 was defined as respiratory failure requiring mechanical ventilation, or shock, or other organ failure (apart from lung) requiring intensive care unit (ICU) monitoring [10]. All patients in our study were clinically classified as having severe COVID19 according to the above criteria.

During the period of hospitalization, respiratory tract specimens (throat swabs) of all patients were continuously monitored for viral shedding until the samples were negative for SARS-Cov-2 RNA for two consecutive days (at least 24 hours apart). This study was approved by the Ethics Committee of the People's Hospital Affiliated to Fujian University of Traditional Chinese Medicine, and the patients provided informed consent for paper publication.

\subsection{Collection, Storage And Use Of Cp}

According to the Clinical Treatment Scheme of COVID-19 Convalescent Plasma [11], CP was obtained from COVID-19 patients who had recently recovered and discharged from the hospital. Before venous blood sample collection, all donors had undergone strict medical screening and evaluation, including meeting the quarantine and discharge standards according to the Diagnosis and Treatment Program for COVID-19 [9], and at least 2 weeks after discharge. Respiratory specimens were negative for SARS-CoV-2 and other viral nucleic acids, and serum tests for hepatitis $B$ virus, hepatitis $C$ virus, human immunodeficiency virus (HIV) and syphilis were negative. Serum SARS-CoV-2 IgG antibody dilution titers of three donors were at least 1:80, and the total CP infusion dose of each patient was 200 to $400 \mathrm{ml}$ (4 to $5 \mathrm{ml} / \mathrm{kg}$ ) (Table 1). Early CP administration was defined as CP infusion initiated within one week after 
admission and two weeks following symptom onset [12-14]. Adverse reactions to CP infusion were closely monitored during CP treatment, and the first efficacy assessment, including clinical symptoms, oxygenation function, inflammatory markers, lymphocyte counts, chest CT manifestations, etc., was performed 48 to 72 hours after transfusion.

Table 1

Characteristics of three patients with convalescent plasma therapy

\begin{tabular}{|c|c|c|c|}
\hline Characteristics & Case 1 & Case 2 & Case 3 \\
\hline Importing nation & Brazil & America & France \\
\hline Nationality & Chinese & Chinese & Chinese \\
\hline Age (years) & 57 & 65 & 59 \\
\hline Sex & Male & Female & Female \\
\hline Body weight (kg) & 82 & 50 & 58 \\
\hline BMI $\left(\mathrm{kg} / \mathrm{m}^{2}\right)$ & 27.7 & 22.2 & 20.3 \\
\hline Disease type & Severe & Severe & Severe \\
\hline Underlying disease & $\begin{array}{l}\text { Hypertension, Sequela of cerebral } \\
\text { infarction }\end{array}$ & Hypertension, diabetes & Postoperative thyroid denoma \\
\hline Symptom & Cough, expectoration, fever, & $\begin{array}{l}\text { Cough, breathlessness, appetite, } \\
\text { excessive fatigue }\end{array}$ & $\begin{array}{l}\text { Cough, fever, breathlessness, dry } \\
\text { thorat }\end{array}$ \\
\hline Chest CT feature & breatnlessness, neadache & \multirow{8}{*}{$\begin{array}{l}\text { Multiple lesions } \\
\text { None } \\
\text { Abidol, lopinavir/ritonavir } \\
\text { None } \\
\text { Xuebijing injection, ulinastatin } \\
\text { Thymalfasin } \\
\text { Yes } \\
\text { Ransnasal catheter oxygen therapy } \\
\text { Type A, negative for RhD }\end{array}$} & Multiple lesions \\
\hline $\begin{array}{l}\text { Complication } \\
\text { Anti-viral treatment }\end{array}$ & None & & $\begin{array}{l}\text { Hypovolemia, pulmonary } \\
\text { bacterial infection }\end{array}$ \\
\hline Antibiotic therapy & Abidol, hydroxychloroquine sulfate & & Human interferona-2b spray \\
\hline Anti-inflammatory agent & None & & Ceftriaxon \\
\hline Immunostimulant & Xuebijing injection, ulinastatin & & Xuebijing injection, ulinastatin \\
\hline Chinese herbal medicine & Thymalfasin & & Thymalfasin \\
\hline Respiratory support & Yes & & Yes \\
\hline Blood type of CPR & Ransnasal catheter oxygen therapy & & $\begin{array}{l}\text { Ransnasal catheter oxygen } \\
\text { therapy }\end{array}$ \\
\hline Blood type of CPD & Type B, positive for RhD & \multirow{3}{*}{$\begin{array}{l}\text { Type A, positive for RhD } \\
\text { Positive at } 1: 80 \text {, Negative at } 1: 160 \\
10\end{array}$} & Type B, positive for RhD \\
\hline SARS-CoV-2 IgG titer of CPD & Iуре $B$, positive for RhD & & Type B, positive for RhD \\
\hline $\begin{array}{l}\text { Timing from onset to CP } \\
\text { infusion (d) }\end{array}$ & 7 & & $\begin{array}{l}\text { Weakly positive at } 1: 80 \text {, } \\
\text { Negative at } 1: 160\end{array}$ \\
\hline $\begin{array}{l}\text { Timing from admission to CP } \\
\text { infusion (d) }\end{array}$ & 2 & \multirow{4}{*}{$\begin{array}{l}2 \\
200 \\
\text { Mild alergic reaction }\end{array}$} & 10 \\
\hline Total CP volume (ml) & 400 & & 7 \\
\hline Adverse reaction related $\mathrm{CP}$ & None & & 200 \\
\hline & & & None \\
\hline
\end{tabular}

\section{Results}

\subsection{Plasma donors (Table 1)}

Plasma was obtained from three COVID-19 patients who had recently recovered and were discharged from the COVID-19 designated hospital in Fuzhou. Among these donors, the anti-SARS-CoV-2 IgG titer in one case (Case 1) was $\geq 1: 160$, and the antibody titers in the other two cases (Case 2 and Case 3 ) were $\geq 1: 80$. One patient (Case 2) with blood type $A$ who was negative for RhD received plasma from a donor with blood type $A$ and positive for RhD, and the other two recipients were treated with complete blood type $\mathrm{ABO}$ and Rh-compatible $\mathrm{CP}$.

3.2 Clinical manifestations, treatment and prognosis of plasma receptors (Tables 1, 2) 
Table 2

Dynamics of indicators during plasma therapy

\begin{tabular}{|c|c|c|c|}
\hline Characteristics & Case 1 & Case 2 & Case 3 \\
\hline Pre-treatment of $\mathrm{CP}$ & 94 & 94 & 93 \\
\hline $\mathrm{SaO}_{2}(\%)$ & 63.9 & 17.6 & 45.9 \\
\hline CRP (mg/L, normal range $0-10)$ & 59.9 & 29.3 & 44.3 \\
\hline IL-6 (pg/ml, normal range <7.0) & 550 & 966 & 541 \\
\hline CD3+ (cells/ $\mu \mathrm{L}$, normal range 955-2860) & 355 & 421 & 305 \\
\hline CD3+CD4+ (cells/ $\mu \mathrm{L}$, normal range $550-1440)$ & 186 & 528 & 228 \\
\hline CD3+CD8+ (cells/ $\mu \mathrm{L}$, normal range $320-1250)$ & 952 & 1331 & 755 \\
\hline Total lymphocyte (cells/ $\mu \mathrm{L}$, normal range $1530-3700$ ) & Improvement & Improvement & Improvement \\
\hline 48-72 hours after $\mathrm{CP}$ treatment & Partially absorption & Partially absorption & Partially absorption \\
\hline Symptom & 97 & 96 & 96 \\
\hline Lung lesion & 25.8 & 5.7 & 9.1 \\
\hline $\mathrm{SaO} 2(\%)$ & 8.1 & 10.3 & 7.2 \\
\hline $\mathrm{CRP}(\mathrm{mg} / \mathrm{L})$ & 818 & 1087 & 872 \\
\hline IL-6 (pg/ml) & 550 & 537 & 583 \\
\hline CD3+ (cells $/ \mu \mathrm{L})$ & 250 & 508 & 282 \\
\hline CD3+CD4+ (cells $/ \mu \mathrm{L})$ & 1298 & 1450 & 1239 \\
\hline CD3+CD8+ (cells/ $\mu \mathrm{L})$ & Sustained absorption & Sustained bsorption & Sustained absorption \\
\hline Total lymphocyte (cells/ $\mu \mathrm{L}$ ) & 98 & 96 & 98 \\
\hline Nine days after $\mathrm{CP}$ treatment & 2.5 & 0.62 & 0.92 \\
\hline Lung lesion & $<1.5$ & $<1.5$ & $<1.5$ \\
\hline $\mathrm{SaO} 2(\%)$ & 707 & 1282 & 958 \\
\hline $\mathrm{CRP}(\mathrm{mg} / \mathrm{L})$ & 468 & 713 & 562 \\
\hline $\mathrm{IL}-6(\mathrm{pg} / \mathrm{ml})$ & 235 & 561 & 358 \\
\hline CD3+ (cells $/ \mu \mathrm{L})$ & 984 & 1651 & 1239 \\
\hline CD3+CD4+ (cells $/ \mu \mathrm{L})$ & 1122 & 2466 & 813 \\
\hline CD3+CD8+ (cells $/ \mu \mathrm{L})$ & 707 & 1041 & 545 \\
\hline Total lymphocyte (cells/ $\mu \mathrm{L}$ ) & 382 & 1345 & 259 \\
\hline 30 days after $\mathrm{CP}$ treatment & 1878 & 3203 & 1074 \\
\hline CD3+ (cells $/ \mu \mathrm{L})$ & 17 & 16 & 33 \\
\hline CD3+CD4+ (cells $/ \mu \mathrm{L})$ & 17 & 13 & 33 \\
\hline \multicolumn{4}{|l|}{ CD3+CD8+ (cells $/ \mu \mathrm{L})$} \\
\hline \multicolumn{4}{|l|}{ Total lymphocyte (cells/ $\mu \mathrm{L}$ ) } \\
\hline \multicolumn{4}{|l|}{ Timing from onset to a negative viral test result (d) } \\
\hline Hospital stay (d) & & & \\
\hline
\end{tabular}

During the study, three severe COVID-19 patients, one male and two females, were enrolled and received CP transfusion. These patients were 57,59 and 65 years old, respectively. The main underlying diseases included hypertension, diabetes, cerebral infarction and postoperative thyroid adenoma. The common symptoms included cough, fever and shortness of breath. Blood laboratory examinations showed a decrease in arterial oxygen saturation $\left(\mathrm{SaO}_{2}\right)$, an increase in C-reactive protein (CRP) and interleukin-6 (IL-6), and a decrease in total lymphocytes (CD45+), T lymphocytes (CD3+) and their subsets (CD4+, CD8+) (Figure 1). Chest CT showed multiple patchy and nodular ground glass opacies, consolidation and linear opacities in both lungs (Fig. 2A, 2B, Fig. 3A, 3B, Fig. 4A, 4B). After admission, all the patients received transnasal catheter oxygen therapy and were given antiviral treatment with arbidol, hydroxychloroquine, sulfatelopinavir/ritonavir or recombinant human interferon $\mathrm{a}-2 \mathrm{~b}$ spray, and one patient was treated with a combination of antibiotics. 
Other medicines, including immunostimulants (thymalfasin), anti-inflammatory agents (Xuebijing injection and ulinastatin) and Chinese herbal medicine, were also administered.

On the basis of conventional treatment after admission, the condition of these patients continued to worsen. Then they all received additional CP therapy. All patients provided informed consent for CP treatment before transfusion. The CP transfusion volume was $400 \mathrm{ml}$ (two consecutive days, $200 \mathrm{ml}$ per day), $200 \mathrm{ml}$ and $200 \mathrm{ml}$. Fourty-eight to seventy-two hours after CP transfusion, all the patients improved with alleviated symptoms, elevated $\mathrm{SaO}_{2}$, decreased CRP and IL-6, and increased lymphocyte counts (Figure 1). Repeated chest CTs also showed obvious absorption of lesions in the bilateral lungs (Fig. 2C, 2D, Fig. 3C, 3D, Fig. 4C, 4D). On days 9 and 30 after CP transfusion, the above indicators continued to improve, and the patients improved until they were discharged stably. The latest outpatient follow-up was performed on May 7th, 2020, when the patients remained well without signs of recurrence.

\subsection{Adverse reactions related to CP transfusion (Table 2)}

One patient (Case 2) developed a red rash with pruritus around the infusion site of the right upper extremity 17 hours after $\mathrm{CP}$ transfusion, and the rash extended to the whole body with pruritus 22 hours after transfusion. Considering the $\mathrm{CP}$ transfusion-related allergic reaction, the patient received antianathylactic treatment with $10 \%$ calcium gluconate infusion and oral ebastines. Then, the symptoms were gradually relieved after treatment, and the rash completely disappeared 5 days after $\mathrm{CP}$ transfusion. No severe adverse reactions were found in any of the patients.

\section{Discussion}

To date, COVID-19 influenza is still rapidly spreading worldwide. Clinical data from China have shown that the severe COVID-19 rate can be as high as $41.1 \% \sim 48.3 \%$ in the early stage of the epidemic $[15,16]$. Due to the rapid progression with high mortality in severe COVID-19 patients, effective treatment is urgently needed to control the deterioration of the disease. However, there are no current proven antiviral drugs that could effectively treat the novel virus [17, 18]. A multicenter trial showed that plasma therapy could accelerate the rate of viral negative conversion and clinical recovery in COVID-19 patients, shorten the length of hospital stay, and reduce the risk of death by $35 \%$ [7]. Ibrahim et al. reported that early application of plasma therapy was helpful to accelerate clinical recovery and reduce mortality [12]. In a large retrospective case-control study, Xia et al. also showed that CP therapy improved clinical symptoms, reduced ICU admission risk, and reduced mortality (the death risk was reduced by 50\%) [19]. Previous studies have also shown that early application of plasma to severe patients was more effective, while the overall benefit of CP in extremely critical patients, such as tracheal intubation or life-threatening conditions, was not significant $[7,12,19,20]$. The three cases in our study were severely elderly patients with basic diseases such as diabetes and high blood pressure but without endotracheal intubation. After admission, the condition of these patients progressed rapidly, and there was a high risk of developing critical illness. Then, CP was administered based on conventional treatment. After the combined therapy, the symptoms were alleviated rapidly, the lung lesions were significantly absorpted, the inflammatory indexes were decreased, and the oxygenation function and cellular immune function were improved. The remarkable improvement of these patients suggests that plasma treatment is an effective remedy for severe COVID-19 patients. Hegerova et al. reported that patients who received CP within one week after admission had a significantly reduced risk of death within 14 days (mortality was 0 ) [13]. The CP treatment time of all patients in our study was within one week after admission (within 10 days after onset), which was significantly earlier than the time reported by Xia et al. (the median time from onset to CP was 45 days) [19]. Significant improvement was achieved within 72 hours of CP treatment in our research, suggesting that early active CP therapy in severe COVID-19 patients becomes even more effective.

Notably, although the three patients improved significantly after CP, one of them (Case 3) remained positive for SARS-CoV-2 RNA for more than one month (33 days). At the beginning of the disease, the lymphocyte counts in the three patients all decreased, and the number of lymphocytes gradually increased after CP, which was consistent with a previous report [5]. However, the lymphocyte counts in one patient (Case 3) were still lower than the normal standards 30 days after $\mathrm{CP}$, whereas the other two patients (Case 1, Case 2) all returned to normal. The prolonged viral removal in Case 3 was considered to be associated with a prolonged period of immunodeficiency. Additionally, the donor plasma antibody titer results showed that the titer in Case 1 was the highest ( $\geq 1: 160$ ), and the titers in the other two patients (Case 2 , Case 3 ) were $\geq 1: 80$, but the antibody titer in Case 3 was only weakly positive at $1: 80$. This suggested that this patient (Case 3 ) received the lowest antibody level of CP in these three patients, which may reduce the plasma efficacy [19].

Additionally, only one patient (Case 2) had a mild allergic reaction with erythema and pruritus at the early period of transfusion, but no other serious adverse reactions were found in the follow-up. As previously described in our paper, the blood type of this patient (Case 2) was type $A$ and negative RhD, which is a rare $\mathrm{Rh}$ blood type. She later received $\mathrm{CP}$ with blood type $\mathrm{A}$ and positive $\mathrm{RhD}$, suggesting that the allergic reaction in this patient might be related to treatment with incomplete Rh-compatible plasma, but other serious adverse reactions, such as acutehemolytic transfusion reaction and shock response, were not found. Generally, plasma treatment in our study was safe and reliable, consistent with the literature reports [19, 21].

Notably, there are some limitations in our research. First, this study was only performed with 3 patients without solid controls (directly compared to patients with $\mathrm{CP}$ and without $\mathrm{CP}$ treatment). Second, the patients were also given other medications (including antiviral drugs, antibiotics, anti-inflammatory agents, immunostimulants and Chinese herbal medicine)/treatment. Hence, this does serve as one of the confounding factors. It could be that these factors might play an important role in recovery as well in synergy with CP treatment. However, there were no proven effective antiviral drugs or other traditional therapies in our study for controlling the novel virus. Combined CP therapy was initiated after the condition worsened with conventional treatment. Additionally, as mentioned previously, patients who received CP earlier can have more favorable clinical outcomes [12]. The CP remedy in our study was utilized in the early disease course. Moreover, the first curative effect evaluation was assessed in a short time after CP transfusion (within 48 to 72 hours), and the findings that showed obvious improvement with clinical symptoms, radiological images and laboratory tests were encouraging. As a result, we think the marked efficiency should be mainly attributed to additional CP treatment. 
In summary, the early application of CP for severe COVID-19 patients can improve the condition rapidly, and the therapy is generally effective and safe. This therapy can reduce the COVID-19 progression risk from severe to critical, lower the mortality rate [22], and is helpful to raise the rescue success rate of severe patients. Due to the absence of effective anti-SARS-CoV-2 drugs, CP therapy is an alternative adjuvant method to treat severe COVID-19 patients [22].

\section{Declarations}

\section{Ethics approval and consent to participate}

This study was in line with the Declaration of Helsinki and approved by the Ethics Committee of the People's Hospital Affiliated to Fujian University of Traditional Chinese Medicine, and the patients provided informed consent to participate.

\section{Consent for publication}

The patients provided informed consent for paper publication.

\section{Availability of data and materials}

All data generated or analysed during this study are included in this published article.

\section{Competing interests}

The authors declare that they have no conflicts of interest for this work.

\section{Funding}

This research did not receive any specific grant from funding agencies in the public, commercial, or not-for-profit sectors.

\section{Authors' Contributions}

$\mathrm{JH}$ conceived of the study, drafted the manuscript, and reviewed all drafts of the manuscript. CL managed the data collection, data analysis, prepared figures 1-4 and tables 1-2 and help tdrafted the manuscript. All authors read and approved the final manuscript.

\section{Acknowledgement}

We would like to thank the Fujian Provincial Medical Treatment Clinical Expert Group for COVID-19, the nurses and clinical staff who provided care for the patient in Fuzhou Pulmonary Hospital of Fujian, and the patient for her willingness to participate in this study.

\section{References}

1. Chinese Medical Association Respiratory Branch, Chinese Medical Doctor Association Respiratory Physician Branch. Expert advice for CoVID-19 Prevention and Control. Chin J Tuberc Respir Dis 2020;43(6):473-89.

2. Bloch EM. Convalescent plasma to treat COVID-19. Blood 2020;136(6):654-5.

3. Mair-Jenkins J, Saavedra-Campos M, Baillie JK, et al. The effectiveness of convalescent plasma and hyperimmune immunoglobulin for the treatment of severe acute respiratory infections of viral etiology: a systematic review and exploratory meta-analysis. J Infect Dis 2015;211(1):80-90.

4. Shen C, Wang Z, Zhao F, et al. Treatment of 5 Critically III Patients With COVID-19 With Convalescent Plasma. JAMA 2020;323(16):1582-9.

5. Duan K, Liu B, Li C, et al. Effectiveness of convalescent plasma therapy in severe COVID-19 patients. Proc Natl Acad Sci U S A 2020;117(17):9490-6.

6. Zhang L, Pang R, Xue X, et al. Anti-SARS-CoV-2 virus antibody levels in convalescent plasma of six donors who have recovered from COVID-19. Aging (Albany NY) 2020;12(8):6536-42.

7. Li L, Zhang W, Hu Y, et al. Effect of Convalescent Plasma Therapy on Time to Clinical Improvement in Patients With Severe and Life-threatening COVID19: A Randomized Clinical Trial. JAMA 2020;324(5):460-70.

8. Casadevall A, Joyner MJ, Pirofski LA. A Randomized Trial of Convalescent Plasma for COVID-19-Potentially Hopeful Signals. JAMA 2020;324(5):4557.

9. National Health Commission of the People's Republic of China. Diagnosis and treatment of novel coronavirus pneumonia (Trial version 7) [D]. Published 2020. Accessed March 3, 2020.<biubold;direction:rtl;vertical-align:baseline;></biubold;direction:rtl;vertical- 
align:baseline;>http://www.nhc.gov.cn/yzygj/s7653p/202003/46c9294a7dfe4cef80dc7f5912eb1989/files/ce3e6945832a438eaae415350a8ce964.pdf

10. Military forward expert group. Diagnosis and treatment program of novel coronavirus infection disease in Military medical team for assisting Hubei (Trial version 2). Chin J Tuberc Respir Dis 2020;43(5): 414-20.

11. Clinical treatment protocol of convalescence plasma for COVID-19 patients (Trial version 2). [EB / OL]. [20200304].http://www.nhc.gov.cn/yzygj/s7658/202003/61d608a7e8bf49fca418a6074c2bf5a2/files/ a5e00234915344c6867a3e6bcfac11b7.pdf

12. Ibrahim D, Dulipsingh L, Zapatka L, et al. Factors Associated with Good Patient Outcomes Following Convalescent Plasma in COVID-19: A Prospective Phase II Clinical Trial. Infect Dis Ther 2020:1-14.

13. Hegerova L, Gooley TA, Sweerus KA, et al. Use of convalescent plasma in hospitalized patients with COVID-19: case series. Blood 2020;136(6):759-62.

14. Rojas M, Rodríguez Y, Monsalve DM, et al. Convalescent plasma in Covid-19: possible mechanisms of action. Autoimmun Rev 2020:102554.

15. Chen L, Liu H, Liu W, et al. Analysis of clinical features of 29 patients with 2019 novel coronavirus pneumonia. Chin J Tuberc Respir Dis 2020;43(3):203-8.

16. Mao L, Jin H, Wang M, et al. Neurologic Manifestations of Hospitalized Patients With Coronavirus Disease 2019 in Wuhan, China. JAMA Neurol 2020;77(6):683-90.

17. World Health Organization Coronavirus disease (COVID-19) pandemic. Available at: https://www.who.int/emergencies/diseases/novel-coronavirus2019. Accessed 9 June 2020.

18. Lu H. Drug treatment options for the 2019-new coronavirus (2019-nCoV). Biosci Trends 2020;14(1):69-71.

19. Xia X, Li K, Wu L, et al. Improved clinical symptoms and mortality among patients with severe or critical COVID-19 after convalescent plasma transfusion. Blood 2020;136(6):755-9.

20. Liu STH, Lin HM, Baine I, et al. Convalescent plasma treatment of severe COVID-19: a propensity score-matched control study. Nat Med 2020;26(11):1708-13.

21. Joyner M, Wright RS, Fairweather D, et al. Early Safety Indicators of COVID-19 Convalescent Plasma in 5,000 Patients. medRxiv [Preprint]. 2020:2020.05.12.20099879. Update in: J Clin Invest. 2020 Aug 10.

22. Wardhani SO, Fajar JK, Wulandari L, et al. Association between convalescent plasma and the risk of mortality among patients with COVID-19: a metaanalysis. F1000Res 2021;10:64.

\section{Figures}




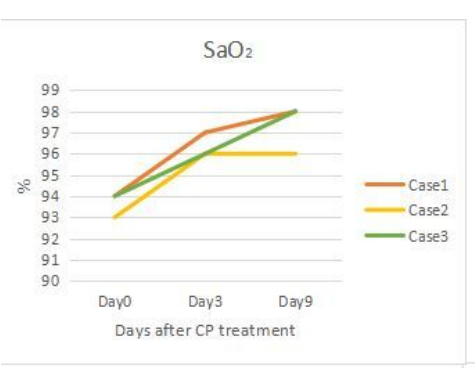

IL-6

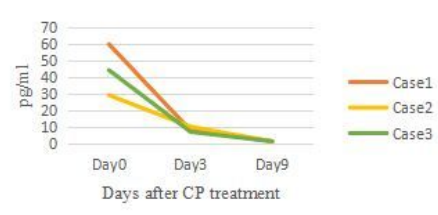

CD3+CD4+ T-lymphocyte

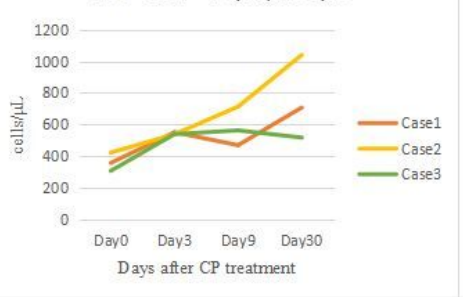

Total lymphocyte

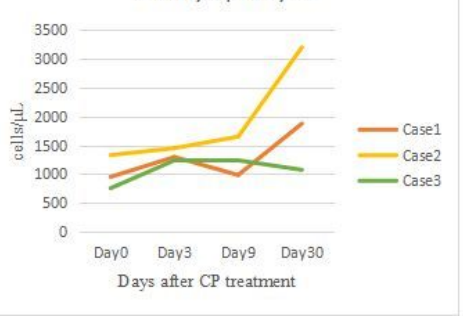

CRP

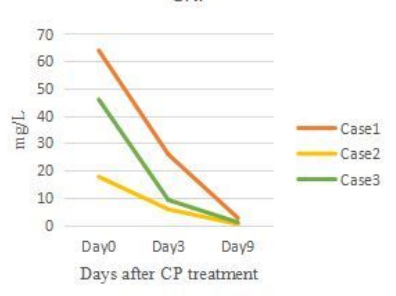

T-lymphocyte (CD3+)

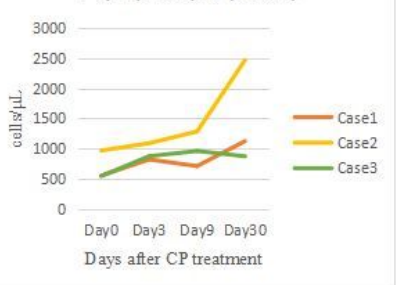

CD3+CD8+ T-lymphocyte

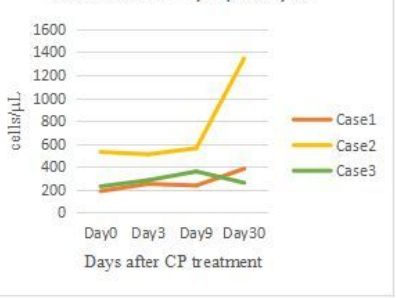

\section{Figure 1}

Dynamics of laboratory indicators after plasma therapy. Dynamics of laboratory indicators after plasma therapy. After plasma therapy, the results showed an increase in arterial oxygen saturation $\left(\mathrm{SaO}_{2}\right)$, a decrease in C-reactive protein (CRP) and interleukin-6 (IL-6), and an increase in total lymphocytes, $\mathrm{T}$ lymphocytes (CD3+) and their subsets (CD4+, CD8+).

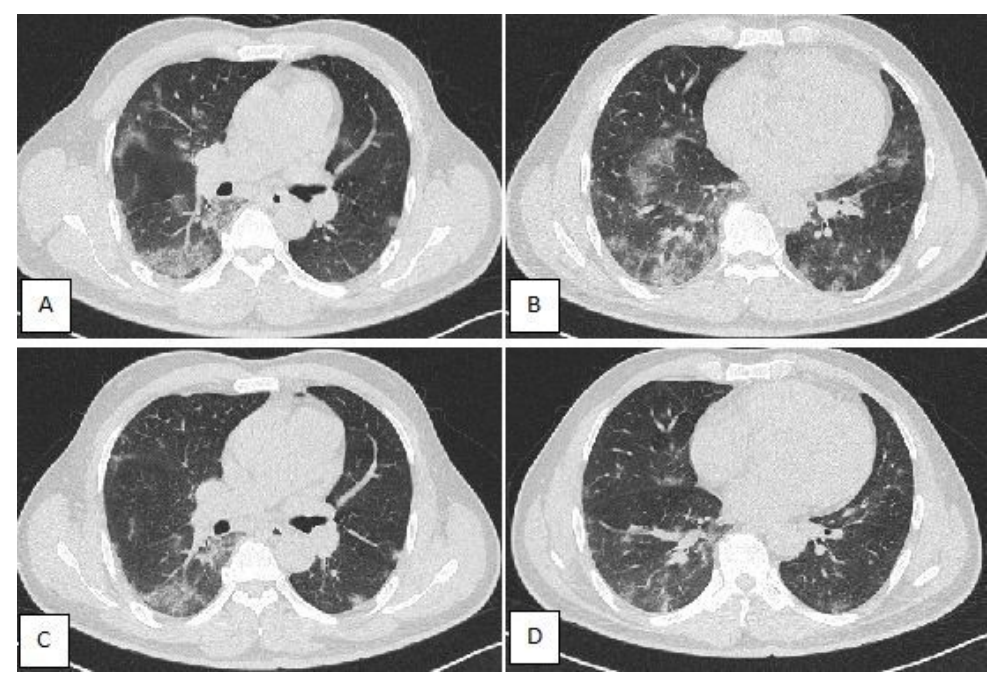

\section{Figure 2}

Case 1. On the second day of admission (the 7th day of onset), chest CT showed patchy and nodular ground glass opacies, consolidation and linear opacities in the bilateral lungs, mainly in both lower lungs (A, B). Seventy hours after plasma treatment, the lung lesions were significantly absorbed (C, D). 


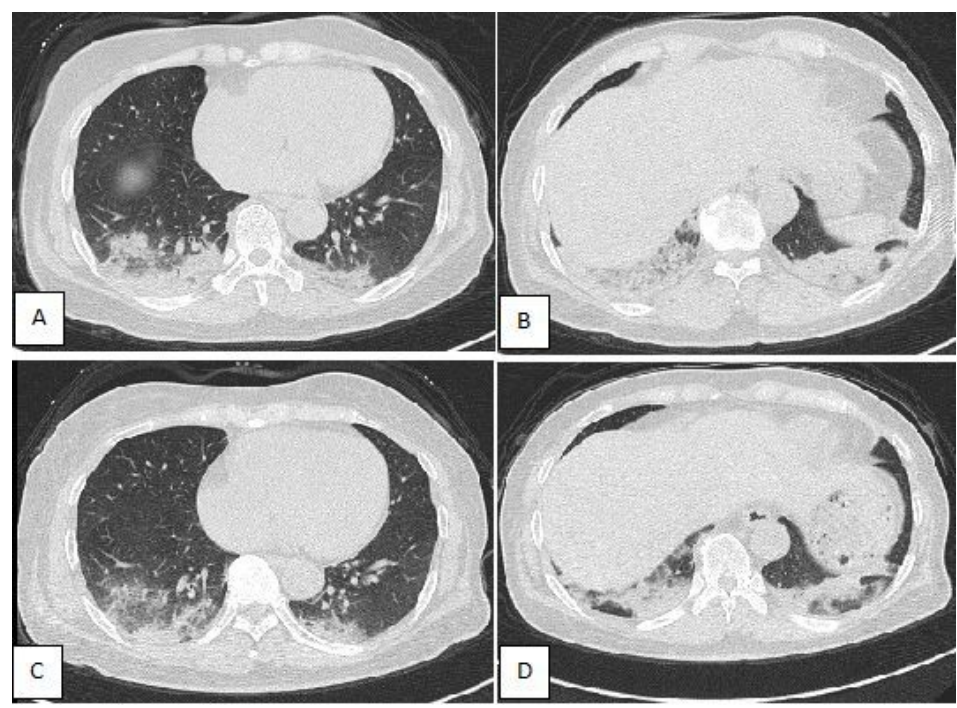

Figure 3

Case 2. On the second day of admission (the 10th day of onset), chest CT showed patchy consolidation and linear opacities in the bilateral lungs, mainly in both lower lungs $(A, B)$. Seventy hours after plasma treatment, the lung lesions were significantly absorbed $(C, D)$.
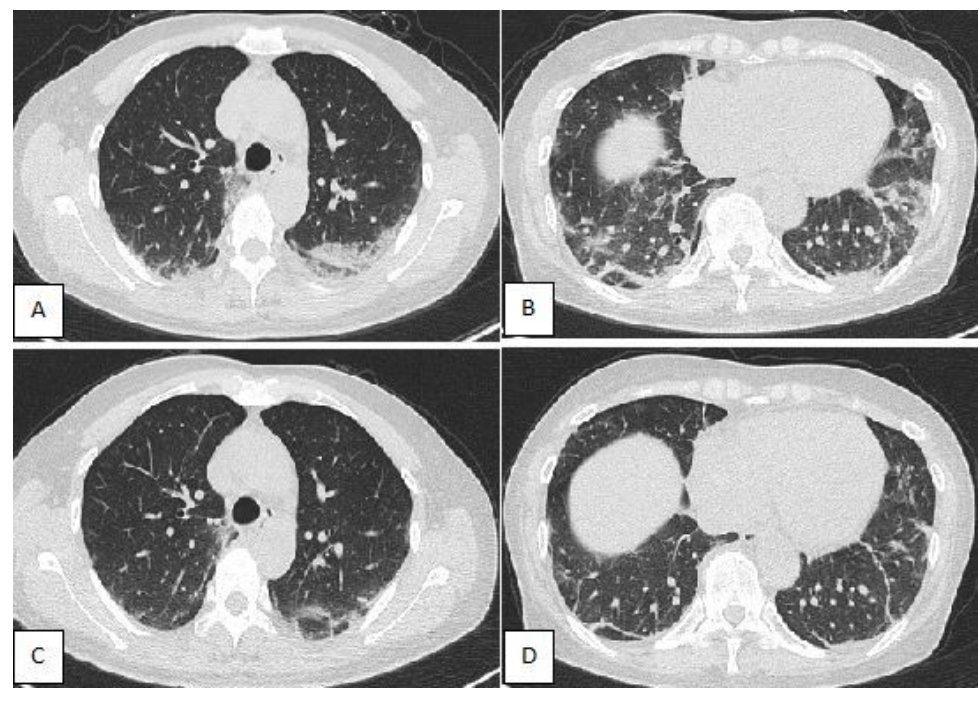

Figure 4

Case 3. On the 7th day of admission (the 10th day of onset), chest CT showed multiple patchy and nodular ground glass opacies, consolidation and linear opacities in the bilateral lungs, mainly in the subpleural area (A, B). Fourty hours after plasma treatment, the lung lesions were significantly absorbed (C, D). 